\title{
Aporia narrativa e humorismo em Boca de Ouro, de Nelson Rodrigues
}

\section{Narrative aporia and humour in Boca de Ouro, by Nelson Rodrigues}

Elen de Medeiros ${ }^{1}$ 


\section{Resumo}

Este artigo propõe uma leitura da estrutura dramática de Boca de Ouro (1959), de Nelson Rodrigues, a partir de procedimentos utilizados pelo autor, tais como a não-presença e o humorismo. Na peça, o dramaturgo coloca em evidência a volubilidade na reconstituição da memória ao projetar à cena três versões diferentes de Boca de Ouro, bicheiro carioca. Sua imagem se constitui miticamente à medida que avança a narrativa movente de suas facetas pela voz de sua ex-amante. Ao reelaborar a descrição do protagonista, o autor estabelece um jogo dramatúrgico igualmente movente, que não se preocupa em responder às lacunas da fábula, compondo assim uma aporia narrativa.

Palavras-chave: Drama rapsódico; drama moderno; Nelson Rodrigues; teatro brasileiro; aporia narrativa

\section{Abstract}

This article proposes a reading of the dramatic structure of Boca de Ouro (1959), written by Nelson Rodrigues, from procedures used by the author, such as non-presence and humour. In the play, the playwright highlights the volubility in the reconstitution of memory by designing three different versions of Boca de Ouro, a bicheiro from Rio de Janeiro. His image is constituted mythically as the moving narrative of its facets advances by the voice of his former mistress. In elaborating the description of the protagonist, the author establishes an equally moving dramaturgical game, which does not care to answer the gaps of the fable, thus composing a narrative aporia.

Keywords: Rhapsodic drama; modern drama; Nelson Rodrigues; Brazilian theater; narrative aporia. 
Não se vê mais a realidade. Vê-se um pouco da realidade (Heiner Müller apud Sarrazac, 2013, p. 90)

\section{Não-presença e metanarrativa: dispositivos dramatúrgicos}

Em seu ensaio O humorismo, Luigi Pirandello coloca em destaque uma discussão acerca das impossibilidades de lidarmos com versões únicas de cada fato. Ao partir da ideia de humorismo como o sentimento do contrário - aquilo que se instaura diante do riso inconsequente, como a consciência crítica que o barra -, ele propõe uma reflexão sobre a multiplicidade da alma humana. Estamos diante de um pensamento que o dramaturgo defenderá ao longo de suas principais peças: "justamente as várias tendências que assinalam a personalidade fazem pensar a sério que a alma individual não seja una" (Pirandello, 2009, p. 168). Isso porque "sentimos em nós mesmos aquela vaidade de parecermos diferentes do que somos, que é uma forma consubstanciada na vida social" (Pirandello, 2009, p. 167).

Esse pensamento levará o teatro de Pirandello a impor uma constante dúvida sobre as certezas, e a multiplicidade de possibilidades - e olhares - coloca suas personagens em estado de imprecisão. Se, em Assim é (se lhe parece), o dramaturgo italiano elabora as contradições a fim de colocar em choque os pontos de vista opostos, em Seis personagens ele atinge seu ponto alto ao jogar com a indicação de busca de uma autoria por parte das personagens, que viveram um drama que não pode ser jamais representado, porque a mimese teatral é incapaz de retratar a realidade vivida. Ali, diante dos olhos incrédulos dos atores, as personagens revivem seu drama e, nesse jogo de metalinguagem, aprofundam as perspectivas que se têm da composição de suas almas - com contradições, visões diversas e incertezas de sentimento. Ao mesmo tempo, a não-presença das personagens no ato teatral aponta para a impossibilidade do drama: existe nesse jogo uma aporia narrativa.

A segunda [Seis personagens à procura de um autor], fingindo se corrigir, coloca em cena a impossibilidade de unificar em um só drama os testemunhos parciais e tendenciosos que carregam, seja em palavras, seja em sua atitude geral, as seis personagens que são apresentadas a ele [o diretor]. ${ }^{2}$ (Sarrazac, 2012, p. 23)

É, portanto, a multiplicidade de versões que impossibilita a realização do drama em Pirandello, cada qual sendo lançada parcialmente, em ações particulares, sem que isso possibilite a união delas para a representação. O impasse se coloca em cena e não há uma saída, uma síntese, que permita ao drama ser levado à cena. O dramaturgo italiano elabora uma crítica ao teatro vigente em seu país, pautado sobremaneira na forma realista de representação.

Outros motivos nos levam a pontuar aproximações entre os dispositivos dramatúrgicos de Boca de Ouro e de Os seis personagens à procura de um autor. Jean-Pierre Sarrazac (2012), ainda sobre a peça de Pirandello, destaca um ponto de partida em comum entre ela e $O$ filho natural, do francês Denis Diderot:

\footnotetext{
${ }^{2}$ Le second [Seis personagens à procura de um autor], en faisant mine de se défausser, met en scène l'impossibilité d'unifier en un seul drame les témoignages partiels et partiaux que portent, soit en paroles, soit dans leur attitude générale, les six personnages qui se son présentés à lui. (Tradução nossa).
} 
Nos dois casos [Seis personagens e O filho natural], há a criação de um mito literário fundado na visitação de um personagem ou do conjunto de personagens. Nos dois casos, o contrato consiste em transformar em obra de arte um drama vivido. $^{3}(2012$, p. 22)

Existe, assim, um ponto de partida comum que desencadeará, na articulação narrativa, o desenvolvimento da arte, pautada no drama vivido, enquanto trato entre as partes. O que se almeja e o que se alcança, no entanto, não necessariamente se concretiza, tornando-se o impasse senão o dínamo para a redação da obra em si.

Com base nesses dois dispositivos narrativos principais, propomos uma leitura de Boca de Ouro, de Nelson Rodrigues, que, à sua maneira, provoca nessa peça semelhante processo de impossibilidade dramática. Na tentativa de colocar em cena o drama de Boca de Ouro - personagem central da peça homônima, bicheiro da zona norte carioca - ou de Leleco e Celeste, o casal suburbano, existe uma incapacidade mimética da narrativa de Guigui. Por outro lado, para encetar a história, é criada uma visita à casa da ex-amante a fim de forjar um furo de reportagem sobre o recém-assassinado. Embora a premissa seja a construção de um texto não-ficcional, jornalístico, as histórias narradas pela ex-amante do bicheiro, sob diferentes impactos psicológicos, variam nas versões sobre o Drácula de Madureira e colocam em suspense a constituição de seu perfil diante dos leitores/espectadores. Dessa forma, constrói-se intuitivamente a figuração de um mito literário no imaginário popular da peça, singularizada pela não-presença física do bicheiro.

\section{Uma autora à procura de Boca de Ouro}

A fábula resumida é relativamente simples: após a morte do bicheiro Boca de Ouro, o jornal $O$ sol deseja obter um furo jornalístico sobre o contraventor, e para isso vai à procura de uma ex-amante dele, Guigui, para que ela conte um caso importante. Guigui, então, narra a história prosaica de Leleco e Celeste, mas em três diferentes versões, guiadas pelo impacto psicológico que sofre. Ao retornar à redação, Caveirinha, o jornalista, descobre que Boca de Ouro fora morto por uma grã-fina de nome Maria Luísa e que, ao matá-lo, ela ainda lhe roubara a dentadura de ouro pela qual era conhecido.

No entanto, na dramaturgia de Nelson Rodrigues, não é a fábula o ponto mais importante - em sua maior parte, é bastante simples, prosaica -, mas sim como ela será contada. Vê-se semelhante procedimento em Vestido de noiva (1943), peça de maior sucesso do dramaturgo, em que o fato simplório da reconstrução da memória de Alaíde se desdobra em camadas narrativas que se bifurcam e se mesclam no desenvolvimento da ação dramática.

Assim, nos interessa diretamente observar como a fábula de um cotidiano é articulada na narrativa de Guigui, dando ensejo a uma forma movente, que se constitui a partir de dois pontos de partida fundamentais: o primeiro, semelhante àquele apontado por Sarrazac na peça de Pirandello, uma visita. É a partir da visita de Caveirinha

\footnotetext{
${ }^{3}$ Dans les deux cas [Seis personagens e $O$ filho natural, il y a création d'un mythe littéraire fondé sur la visitation d'un personnage ou de l'ensemble des personnages. Dans leus deux cas, le contrat consiste à ériger en oeuvre d'art un drame vécu.
} 
a Guigui que se dá início ao processo mnemônico da narradora e se desenrolam os fatos; segundo, o acordo firmado entre os dois é a elaboração de uma matéria jornalística, capa da edição seguinte de $O$ sol, que será um dos maiores furos jornalísticos referentes à morte de Boca de Ouro. Firmado isso, teremos em cena um protagonista à procura de um drama, da consolidação de sua história - que, não à toa, seguindo as premissas da ironia rodriguiana, não se consolida como verdade - , a exemplo, portanto, do que ocorre com as seis personagens que almejam colocar suas histórias em cena. Com isso, o que vemos efetivamente realizado é a constituição da obra dramática em si.

Muito já se falou do caráter mítico da personagem de Boca de Ouro - dado incluído na própria peça, na rubrica de apresentação do terceiro ato: "De ato para ato, mais se percebe que 'Boca de Ouro' pertence muito mais a uma mitologia suburbana do que à realidade normal da Zona Norte" (Rodrigues, 1985, p. 312) - e do quanto tal caráter marcará a instabilidade do personagem a partir das múltiplas facetas apresentadas. No entanto, é pela forma dramática adotada que chegamos à principal impossibilidade da peça, e que produz nela o efeito fugidio. Trata-se de um texto que escapa à lógica argumentativa das interpretações realistas, como foi lido o teatro rodriguiano por muito tempo. Ao contrário, esta é uma dramaturgia que mostra a impossibilidade de representar no palco uma única verdade. $O$ jogo de não-presença e a aporia narrativa são utilizados como estopim para a reconstrução da memória, que é, basicamente, a elaboração deste drama impossível.

É comum, e tem certa precisão, afirmar que a única parte em que nos deparamos com a personagem Boca de Ouro é a primeira cena, quando, no dentista, o bicheiro the pede que arranque todos seus dentes, sadios, e lhe implante uma dentadura de ouro. Diante da resistência do profissional, o bicheiro insiste e lhe compra o serviço por alto valor, desfazendo a ética do dentista. Além disso, é nesse momento, a que estamos chamando aqui de prólogo, que a personagem revela sua obsessão pelo ouro, já que almeja ser enterrado em um caixão feito do nobre material, e também sua fúria por se consolidar como o Boca de Ouro: "Agora é que, com audácia e imaginação, começa a exterminar os seus adversários" (Rodrigues, 1985, p. 261).

Ismail Xavier, aliás, alinha esse anseio do personagem, protagonista ambientado da zona norte carioca, com os sonhos de Bovary suburbana de Zulmira, em A falecida.

Para compensar o nascimento na pia de gafieira e corrigir o que o incomoda como "mancha de origem", o Boca de Ouro sonha com a glória do caixão de ouro e planeja seu enterro como coroamento da grande vingança sobre a sociedade. [...]. Para afrontar a prima Glorinha, compensar sua pouco importância diante dos vizinhos e vingar-se da vida e do marido, Zulmira planeja seu próprio enterro como quem tece os cordéis de um grande crime [...]. (Xavier, 2003, p. 255)

Tal qual nessa peça, Boca de Ouro não obtém sucesso, fato que é revelado na cena seguinte, quando o secretário de $O$ sol abre a cena gritando: "Mataram o 'Boca de Ouro" (Rodrigues, 1985, p. 264). A morte, revelada desde o início, desnuda o mistério que poderia ser sustentado quanto ao desfecho do protagonista, restando-lhe pouco mais do que uma história pitoresca para ilustrar a edição matinal do periódico. "Ao Boca de Ouro e a Zulmira, o destino reserva o grande logro de um miserável 
enterro à vista de todos, não lhes dando a chance dessa derradeira revanche em que tanto se empenharam" (Xavier, 2003, p. 255).

Nas cenas que se seguem após o prólogo da peça, vemos crescer a imprecisão da figura de Boca até se inserir no que o dramaturgo chama de mitologia suburbana: com ele morto, inicia-se um processo para tentar desvendar sua verdadeira imagem. É sob a responsabilidade de Caveirinha, repórter de $O$ sol, que confiamos os caminhos de investigação sobre a vida e o caráter do bicheiro; e é a Guigui, ex-amante de Boca, que confiamos a lembrança mais fidedigna dele.

Uma vez que temos uma não-presença - que não é precisamente a ausência, mas a rememoração de um alguém que não se coloca enquanto presença -, as versões projetadas por Guigui sobre o ex-amante, Leleco e Celeste se fundamentam na dúvida, na incerteza e geram desconfiança. Manipuladas de acordo com o desejo da narradora, as versões são colocadas à frente do espectador como questionadoras da versão anterior, alterando detalhes, momentos, perfis, anseios.

Com a desestruturação da narrativa linear e da figura do protagonista, projeta-se na forma dramática aquilo que estamos chamando de aporia narrativa. Ou seja, não existe a propensão de resolver o embate entre as versões e declarar qual delas é o verdadeiro Boca de Ouro, mas sustentar a insolubilidade de compreender exatamente quem foi o bicheiro, o Drácula de Madureira: assassino e malfeitor, lorde que paga caixão para os pobres, benevolente, cancro social? Estamos diante de uma personagem que, por meio do jogo de memória, procura se efetivar na voz de sua narradora, mas que se coloca como fantasma de um passado irresoluto. Temos a autora; o que falta é a personagem real.

\section{O humorismo em Boca de Ouro}

O humorismo de Pirandello se constrói com base no que ele chama de sentimento do contrário: a partir de uma percepção crítica, podemos observar que o que está à nossa frente não é o que se vê, mas a possibilidade de múltiplas interpretações para fatos, pessoas, histórias. O que o leva a pensar nisso é a relação que temos com a vivência social, marcada por um agora, um tempo já vivido e quiçá esquecido, lado a lado com as percepções e estados de consciência:

Os limites de nossa memória pessoal e consciente não são limites absolutos. Do outro lado dessa linha são memórias, são percepções e raciocínios. O que nós conhecemos de nós mesmos não é senão uma parte, talvez uma pequeníssima parte daquilo que nós somos. (Pirandello, 2009, p. 169)

O que o dramaturgo siciliano realiza, com base nessa reflexão sobre a impossibilidade de univocidade, é a fluidez da vida, que se coloca diante do artista como múltipla e não estagnada. Ele quebra, dessa forma, a ideia de representação mimética e estática da realidade pelo teatro, especificamente a forma de retratar a sociedade burguesa, apontando assim para as relações intrínsecas à vivência do homem consigo mesmo e em sociedade: "A vida é um fluxo contínuo que nós procuramos deter, fixar em formas estáveis e determinadas, dentro e fora de nós, porque nós já somos formas fixadas [...]" (Pirandello, 2009, p. 169). 
Embora Nelson Rodrigues tenha negado qualquer relação com o teatro de Luigi Pirandello 4 e tenha utilizado bastantes referências do teatro norte-americano de Eugene O'Neill, à medida que o dramaturgo brasileiro elabora suas peças tendo como base a memória - do personagem-narrador ou de outrem -, inevitavelmente nos aproximamos de certa formulação pirandelliana. De todo modo, o teatro de Nelson Rodrigues, amplamente um teatro da memória, está posto como questionador da realidade mimética, seja pela distorção expressionista da realidade (cf. Fraga, 1998), seja pela subversão dos paradigmas com um fundo falso (cf. Sussekind, 1977).

O humorismo pirandelliano, como já observado, distancia-se do cômico, este lido como um advertimento do contrário. Se, em um primeiro momento, podemos rir de algo ou alguém pelo advertimento do contrário, uma percepção de que há algo fora de sua real identificação, o humorismo se instala quando esse riso se transforma em uma percepção crítica, o sentimento do contrário, de que o deslocamento não é proposital ou consciente. O humorismo, portanto, se difere do cômico porque ele aponta para as possíveis variações daquela realidade, escondidas sob uma máscara não tão glamorosa.

Não raro podemos observar filigranas risíveis no teatro rodriguiano. Um detalhe prosaico, um elemento grotesco que se manifesta na minúcia da composição de uma personagem, o rebaixamento de um elemento sublime. De longe, risível; de perto, incômodo. O riso nesse teatro não se aproxima da comicidade leve; assemelha-se, isto sim, a uma percepção amarga de derrocada da vida. É por meio de certo incômodo, diante do que se vê ou lê, que talvez possamos reconhecer o sentimento do contrário, justamente quando são percebidas camadas escondidas sob a realidade visível.

Em um primeiro momento, o desejo suburbano de Celeste pode parecer risível, especialmente pela singeleza do seu sonho: ir à Europa para ver a Grace Kelly. Ou talvez possamos esboçar um riso torto ao observar seus trejeitos de moça de periferia. Mas lidar com o fato de que Celeste, fria com o marido, recorre a amantes para alcançar seu sonho, e que isso é uma forma de se libertar de uma vida sem grandes projeções, pode ser amargo o suficiente a ponto de cortarmos o riso diante das limitações da personagem. Celeste é uma menina do subúrbio da zona norte carioca que, de certa forma, sonha em sair daquele universo sem expectativa, mas o único caminho possível são os amantes ricos.

Leleco - Ouve. Não chora! Você não pode ter amor por esse velho. É dinheiro. ( $r i$ sórdido) Mulher não gosta de homem, gosta é amarelinha no bolso. Mas eu tenho examinado tua bolsa, tenho remexido as tuas gavetas. Até hoje, não vi tostão! (furioso) Onde é que você enfia o dinheiro? O dinheiro que o velho te dá?

Celeste - Não me dá nada!

Leleco - Se me traíste sem amor, por que me traíste? Mas se não é dinheiro, não é amor, então que é?

(Pausa.)

Leleco (berrando) - Fala!

Celeste (com uma serenidade doce e sonhadora) - Esse senhor prometeu que me levaria à Europa para ver a Grace Kelly! (Rodrigues, 1985, p. 296)

\footnotetext{
4 “Em 1943, ninguém sabia, aqui, da existência de Eugene O’Neill; o único autor que se usava, com abundância, era Pirandello. Qualquer coisa que não fosse uma chanchada ignominiosa era pirandelliana; qualquer autor que não fosse um débil mental virava um Pirandello indígena". (Rodrigues, 2004, p. 274)
} 
Pode parecer bastante risível - e é inicialmente - o anseio da jovem suburbana de ver Grace Kelly. Mas se por um instante pararmos para pensar no símbolo que foi a atriz plebeia que largou o sucesso hollywoodiano para se tornar princesa de Mônaco, isso nos leva a perceber as nuances desse desejo prosaico: projetando os seus anseios, Celeste mira-se na jovem e bela atriz para tentar fugir daquele cotidiano que a cerca, de falta de perspectivas e esvaziado de sonhos.

Por meio de micronarrativas - de Celeste, grã-finas, Leleco -, Guigui explora as minúcias da narrativa insolúvel, dando contornos humorísticos, no sentido pirandelliano, à sua memória recriada. E são essas fragmentadas histórias que vão mover cada vez mais a macronarrativa da peça para o lugar da aporia: a cada versão, os fatos são diferentes, as personagens se alteram, os perfis se tornam mais complexos.

Um exemplo mais pontual dessa mutabilidade é a referência à mãe de Celeste. Na primeira versão, que compõe o primeiro ato, ela está doente e à beira da morte. Somente após a ida de Leleco à casa de Boca é que se tem notícia de seu falecimento. No segundo ato, a notícia da morte da mãe de Celeste é dada antes de sua visita ao bicheiro, tão logo Celeste chega em casa e encontra o marido. Por fim, no terceiro ato, Celeste comenta: "Te juro. Minha mãe morreu outro dia. Te juro pela alma de minha mãe" (Rodrigues, 1985, p. 318). Detalhe minucioso que, a despeito da superficialidade do dado, aponta para a mudança da história em torno do casal.

Nesse sentido, a personagem de Boca de Ouro é apenas o ponto de partida da aporia narrativa que se coloca na peça homônima, mas ela se consolida efetivamente a partir das lentes da narradora Guigui. É, portanto, por meio das micronarrativas subjacentes à narrativa maior - aquela ligada ao bicheiro - que se estabelecem as encruzilhadas de Guigui, quando, na reconstrução da história de Leleco e de Celeste, além da própria história com Boca de Ouro, a narradora provoca o humorismo no seu ouvinte. Ao ofertar uma história de um "crime bacana" cometido pelo Drácula de Madureira, Guigui rouba os holofotes para si, apontando para as pistas falsas sobre o ex -amante, mas também sobre sua própria relação com o bicheiro. Ela se projeta como personagem instável e desenha uma outra personagem indefinível, apenas pelo desejo de montar uma narrativa e aparecer na capa do jornal. Narrativa esta que que se estabelece em dois níveis de observação: o primeiro, por Caveirinha, no âmbito da peça; e o segundo, do espectador, que dá conta da narrativa global, encontrando ali camadas ficcionais tais como um mise en abîme.

Se Boca não terá seu caixão de ouro e será enterrado de forma quase indigente, Caveirinha obtém seu êxito: a informação de que precisa para a sua big história. Ao procurar uma confissão da ex-amante sobre um crime qualquer, ele consegue detalhes praticamente dos bastidores que envolvem o morto e sua assassina, Maria Luísa. Guigui se reconcilia com o marido, Agenor, mas os leitores não saberão ao certo quem foi Boca de Ouro e se ele realmente matou ou não Leleco e Celeste.

\section{O drama rapsódico}

Foi Décio de Almeida Prado quem primeiro apontou a proximidade de Boca de Ouro com o filme do cineasta japonês Akira Kurosawa, Rashomon, de 1950, cuja história se centra nas versões diferentes de um crime, narradas por quatro testemunhas 
além do próprio criminoso. Aqui, no entanto, a história sofre alterações advindas da mesma narradora, que não se esquiva de alterar a versão do crime em virtude de seu interesse junto a seu visitante, o repórter de $O$ sol.

Em um jogo de monta e desmonta, de versões diferentes a cada ato e deslocamento de dados, com o acréscimo ou a retirada de personagens ao bel prazer da narradora, vê-se na constituição da forma dramatúrgica da peça um movimento semelhante ao que Sarrazac denomina como rapsódico: "[o] escritor-rapsodo, que junta o que previamente despedaçou e, no mesmo instante, despedaça o que acabou de unir" (2002, p. 37). E se a forma rapsódica do drama moderno dá conta de fragmentos que se unem em uma espécie de patchwork, Boca de Ouro aponta ainda mais para a ruptura dos elementos fundamentais do drama ao levá-los ao desvanecimento de um senso comum de realidade. Dessa maneira, vemos na obra o questionamento de uma forma fixa de narração, porque a fluidez dos acontecimentos sugere a impossibilidade de estancar os fatos em apenas uma realidade. Em suma, trata-se de uma crítica semelhante àquela de Pirandello em seu teatro, direcionando sempre para sentidos subjacentes ao que se vê.

É a aporia narrativa, desencadeada pelos flashbacks contraditórios de Guigui, narradora-rapsoda, que indica um drama extenuado e explorado pelo dramaturgo. Nelson Rodrigues não se esquiva de utilizar os recursos dramáticos, embora não o faça de forma convencional. "Modernas prosaicas", tal como Ismail Xavier (2003) definiu suas personagens, elas transitam entre o universo do cotidiano urbano e o primitivismo de seus instintos e desejos, e carregam consigo a representação moderna e não mimética do homem social diante de sua condição de vida. Aparentemente burguesas, com anseios mesquinhos, essas personagens carregam o fundo falso de que fala Flora Sussekind (1977) e desnudam a imagem moral da burguesia nacional, mascarada pelas convenções sociais.

Da mesma forma como há uma aporia na reconfiguração do bicheiro carioca, igualmente reconhecemos a impossibilidade de definir um perfil claro e realista para Guigui. De caráter movediço, ela se ajusta à necessidade imediata, amparada por um instinto de vingança, amor e sobrevivência. Em um constante deslocamento fabular, ela constrói e desconstrói uma mesma imagem, realocando os dados conforme lhe interessa montar a imagem do protagonista.

Por meio dos fragmentos de narrativas, histórias que compõem as personagens, somos tentados a remontar cada retalho para definir um todo, na nossa ânsia de verossimilhança. No entanto, parte do jogo dramatúrgico de Nelson Rodrigues se encontra nessa impossibilidade de recompor uma história fidedigna, e é nesse vaivém ficcional que se elabora a modernidade rapsódica do drama rodriguiano. Uma obra moderna que, a despeito de ser construída a partir de fragmentos e de alargar as principais formulações dramáticas, ainda assim preza pela urdidura textual. Esta é, enfim, uma obra que se instaura justamente na ineficácia da verossimilhança, da mimese teatral, e o que vemos a cada momento são pistas falsas jogadas ao leitor/ espectador, em um movimento de constante questionamento da realidade vista ou vivida. Diante desse teatro, nada nos resta senão duvidar do que vemos e compreender que a alma não é una. 


\section{Referências}

FRAGA, Eudinyr. Nelson Rodrigues expressionista. Cotia: Ateliê Editorial, 1998.

MÜLLER, Heiner. Le refus d'une vision globale. Entrevista com Olivier Ortolani. In: Théâtre/Public, n. 98, p. 70. Mar-abr. 1991.

PIRANDELLO, Luigi. Do teatro no teatro. Trad. e org. J. Guinsburg. São Paulo: Perspectiva, 2009.

RODRIGUES, Nelson. Teatro completo. vol. 3. Rio de Janeiro: Nova Fronteira, 1985.

RODRIGUES, Nelson. Teatro desagradável. In: RODRIGUES, Nelson. Teatro completo. vol. 1. 2. ed. Rio de Janeiro: Nova Fronteira, 2004.

SARRAZAC, Jean-Pierre. O futuro do drama. Trad. Alexandra Moreira. Porto, Campo das Letras, 2002.

SARRAZAC, Jean-Pierre. Poétique du drame moderne. Paris, Seuil, 2012.

SARRAZAC, Jean-Pierre. Sobre a fábula e o desvio. Org. e trad. Fátima Saadi. Rio de Janeiro, Folhetim/7 Letras, 2013.

SUSSEKIND, Maria Flora. Nelson Rodrigues e o fundo falso. In: I Concurso nacional de monografias - 1976. Brasília: MEC/SNT, 1977.

XAVIER, Ismail. O olhar e a cena. São Paulo: Cosac Naify, 2003.

Recebido em: 20/09/2017

Aprovado em: 20/10/2017 